\title{
Case Control Study of Post-endoscopic Variceal Ligation Bleeding Ulcers in Severe Liver Disease: Outcomes and Management
}

\author{
Kapil D. Jamwal*1,2,3, Rakhi Maiwall², Manoj K. Sharma², Guresh Kumar ${ }^{4}$ and Shiv K. Sarin ${ }^{2}$ \\ ${ }^{1}$ Department of Gastroenterology, Artemis Hospital Gurugram, Haryana, India; ${ }^{2}$ Department of Hepatology, Institute of Liver and \\ Biliary Sciences, New Delhi, India; ${ }^{3}$ Department of Gastroenterology, Dharamshila Narayana Superspeciality Hospital, New Delhi, \\ India; ${ }^{4}$ Department of Research and Biostatistics, Institute of Liver and Biliary Sciences, New Delhi, India
}

\begin{abstract}
Background and Aims: The management of post-endoscopic variceal ligation (EVL) bleeding ulcers (PEBUs) is currently based on local expertise and patients liver disease status. The present retrospective study investigated associations between the endoscopic morphology of PEBUs and patient outcomes. Methods: Patients underwent EVL (primary or secondary), from January 2015 to January 2018, in two tertiary care hospitals in India (ILBS New Delhi and Dharamshila Narayana New Delhi). Mortality rates were determined at post-EVL day five and week six. PEBUs were typified based on Jamwal \& Sarin classification system as follows: A, ulcer with active spurting; $B$, ulcer with ooze; $C$, ulcer base with visible vessel or clot; and D, clean or pigmented base. Results: Of 3854 EVL procedures, 141 (3.6\%) patients developed PEBU, and $46 / 141(32.6 \%)$ suffered mortality. Among the former, the PEBU types A, B, C, and D accounted for 17.7, 26.2, 36.3 , and $19.8 \%$, respectively. Of those who died, 39.1, 30.4, 21.7 , and $8.8 \%$ had PEBU types A, B, C, and D. Treatments included transjugular intrahepatic portosystemic shunts (TIPS), esophageal self-expandable metal stent (SEMS), glue and sclerosant injection, Sengstaken-Blakemore tube placement and liver transplant. On univariate analysis, no correlation with hepatic venous pressure gradient, TIPS placement, size of varices, or number of bands was found. The Model for EndStage Liver Disease (MELD)-sodium score correlated positively with outcome. After adjusting for MELD-sodium score, mortality was best predicted by type-A ulcer ( $p=0.024$; OR $8.95, \mathrm{CI}$ 1.34-59.72). Conclusions: PEBU occurred in $3.6 \%$ of a large EVL cohort. Stratifying patients based on PEBU type can help predict outcomes, independent of the MELD-sodium score. Classifying PEBUs by endoscopic morphology may inform treatment strategies, and warrants further validation.
\end{abstract}

Citation of this article: Jamwal KD, Maiwall R, Sharma MK, Kumar G, Sarin SK. Case control study of post-endoscopic variceal ligation bleeding ulcers in severe liver disease: Outcomes

Keywords: Post-endoscopic variceal ligation bleeding ulcers; Severe liver disease; Case control study; Clinical outcomes.

Abbreviations: CTP, Child-Turcotte-Pugh; EVL, endoscopic variceal ligation HVPG, hepatic venous pressure gradient; MELD-Na, model for end-stage liver disease-sodium; TIPS, transjugular intrahepatic porto systemic shunt. Received: 29 November 2018; Revised: 18 January 2019; Accepted: 25 January 2019

*Correspondence to: Kapil D. Jamwal, Department of Gastroenterology, Artemis Hospital, Gurugram, Haryana 122001, India. Tel: +91-1245111111, E-mail: drkapil222@gmail.com and management. J Clin Transl Hepatol 2019;7(1):32-39. doi: 10.14218/JCTH.2018.00059.

\section{Introduction}

Portal hypertension can present clinically with bleeding due to varices (esophageal or gastric) or other causes. ${ }^{1,2}$ Esophageal variceal bleeding can be classified as primary or secondary, or as post-endoscopic variceal ligation (EVL) bleeding ulcer (PEBU). Non-variceal bleeding in portal hypertension may be due to portal hypertensive gastropathy, gastric antral vascular ectasia, ectopic varices, or causes related to peptic ulcer, Dieulafoy's lesion, or others. ${ }^{2-4}$

PEBU is of unclear etiology, with varied risk factors and undefined clinical outcomes. ${ }^{5}$ Remarkably, there is no clinical or endoscopic classification based on the morphology of these lesions (ulcers), or which associates endoscopic appearance with clinical outcomes.

The available literature, in various case series and reports, suggests that PEBU occurs at rates of $2 \%$ to $10 \%,{ }^{5-7}$ but there is no prospective data for incidence or risk factors. Studies have proposed that PEBU may be caused by reflux of gastric acid into the lower esophagus, leading to exposure of ulcer(s) and underlying vein(s) to the acid. Alternate explanations include slippage of bands, infection of ulcers, and coagulopathy that leads to increased bleeding. Studies have indicated increased risks associated with the number of deployed bands, size of varices, severity of liver failure, or if the endoscopy was performed in an intensive care or emergency setting. 5,7

This study characterized the various endoscopic morphologies of PEBUs with a classification system, and then investigated each of the 4 defined PEBU types for associations with risk of mortality. The study included an evaluation of a large cohort of patients who underwent EVL with subsequent PEBU, relative to patients who did not experience such bleeding.

\section{Methods}

\section{Study population and study design}

The study population comprised 141 patients who had undergone EVL at the Institute of Liver and Biliary Sciences and Dharamshila Narayana Hospital, and who had presented from January 2015 until January 2018 with post-EVL bleeding diagnosed as PEBU via endoscopy. Also included in the 
analysis was a control group of equal size and clinical profile (including severity of liver disease), who had also undergone EVL (primary or secondary) during the same time interval, but did not experience PEBU. Patients who had undergone EVL in another hospital were excluded, to avoid heterogeneous data such as the number of bands deployed, duration of each procedure, expertise of the endoscopist, and clinical parameters at the time of endoscopy.

All the included patients were aged 18 to 80 years, able to give valid consent, and had a reliable history with 3 or more months of post-EVL follow-up. Patients with any of the following were excluded: incomplete post-procedural follow up, 5-day, or 6-week records; pregnancy; or critical illness with contraindications for endoscopy, such as severe hemodynamic instability that required Sengstaken-Blakemore (SB) tube placement, or emergency TIPS. All the patients were prescribed PPI's and oral sucralfate syrup twice a day for 2 weeks.

The esophageal varices were classified as small $(<5 \mathrm{~mm})$ and large $(>5 \mathrm{~mm})$ at the time of the endoscopic examination, both at the time of EVL or during bleeding. The patients undergoing secondary EVL were already on beta blockers, or had begun after bleeding, and the dose was titrated according to heart rate and systolic blood pressure, as standard. Almost all the patients were admitted for observation, and further course of management depended upon the individual's clinical status: daycare admission, or management in intensive care or high dependency units. Measurement of the hepatic venous pressure gradient (HVPG) of a few patients was conducted as a part of another ongoing study.

The liver disease severity was assessed using MELD-Na score and CTP score.

It is a retrospective study with patients recruited from both the centers, the primary outcome was five day and the secondary outcome was six week survival after the bleeding episode.

\section{Definitions}

The various definitions were in accordance with the guidelines of the Asian Pacific Association for the Study of the Liver (APASL). Acute variceal bleeding and variceal rebleeding were defined, respectively, as patient presentation at the hospital within or more than 48 hours after EVL. ${ }^{1,8}$

\section{Endoscopy details}

The endoscopy procedure was generally conducted either in the endoscopy suite or in the ICU at the bedside, depending upon the patient's clinical status. All the patients with bleeding underwent endoscopy within 6 to 12 hours of presentation in the emergency room or outpatient clinic.

The patient was placed in the left lateral position. If the endoscopy was elective, the patient was under conscious sedation administered by an experienced anesthetist. If the endoscopy was performed in an emergency setting and the patient was hemodynamically stable, actively bleeding, and conscious, a topical sedation was used. However, if the patient was hemodynamically unstable or presenting with Grade II-IV encephalopathy, elective endotracheal intubation was implemented before the endoscopy. The endoscopes used were either an adult gastroscope Olympus GIF-180, Olympus GIF-150, or a single-channel therapeutic gastroscope Olympus GIF-1T160 (Olympus Medical, Tokyo, Japan).

\section{PEBU classification}

The PEBUs were classified based on their endoscopic appearance in descending order as types A, B, C, and D, in accordance with the Jamwal \& Sarin classification of PEBU, as follows (Table 1, Figs. 1-4, respectively). Each type included ulcers with or without EVL bands in situ. In type A, there was active spurting from the ulcer. Type $B$ was characterized as active oozing from the ulcer. In Type $C$, the ulcer appeared with a pigmented base or a visible clot. The type D PEBU ulcer had a clean base (white or yellow). If at the time of endoscopy the patient had more than one type of ulcer, then the higher order was chosen.

\section{Statistical analysis}

The data was analyzed with SPSS 22 software and the PEBU and control groups were compared using the paired or unpaired $t$-test. The univariate and multi variate regression analyses was used for study variables.

\section{Results}

From January 2015 until January 2018, 3854 EVL procedures were performed and 141 of the patients presented with PEBU (hematemesis or melena; Table 2). The mean age of the PEBU population was 46.1 years, and the majority were men (91\%). Most of the patients with PEBU presented within 10 to 13 days after the EVL (range, 3-21 d). Fifty-four patients underwent HVPG, with a median measurement of $18 \mathrm{mmHg}$. TIPS was performed in 19 patients, and the median number of applied bands was 3.5 (range, 2.75-5.0). Forty-nine patients showed alterations of the mucosa in the lower esophagus, specifically either neovascularization or scarring, or both. Eighty-eight patients had esophageal mucosa that appeared normal, with either esophageal varices or post-EVL ulcers. Eleven patients who presented with bleeding showed portal vein thrombosis on imaging.

The control group had undergone EVL for indications similar to the case group (either primary or secondary depending on the departmental policy), and none of them experienced post-EVL bleeding.

The PEBUs were classified as described in the Methods (Table 1). Of the 141 patients with PEBU, 23 had more than one type, specifically six with types $A$ and $B, 12$ with types $B$ and $C$, and five with types $C$ and D.

\section{Mortality}

Over the follow-up of 6 weeks, among the patients with PEBUs who suffered mortality, the PEBU types A-D accounted for $18(39.1 \%), 14(30.4 \%), 10(21.7 \%)$, and $4(8.8 \%)$, respectively. Seven patients in the control group died due to

Table 1. PEBU types based on the Jamwal \& Sarin classification

\begin{tabular}{lll}
\hline & Morphological appearance & $n(\%)$ \\
\hline A & Ulcer with spurting & $25(17.7)$ \\
B & Ulcer with ooze & $37(26.2)$ \\
C & Ulcer with clot or pigmented base & $51(36.3)$ \\
D & Ulcer with clean base & $28(19.8)$ \\
\hline
\end{tabular}


Jamwal K.D. et al: Post-EVL bleeding ulcers in liver disease

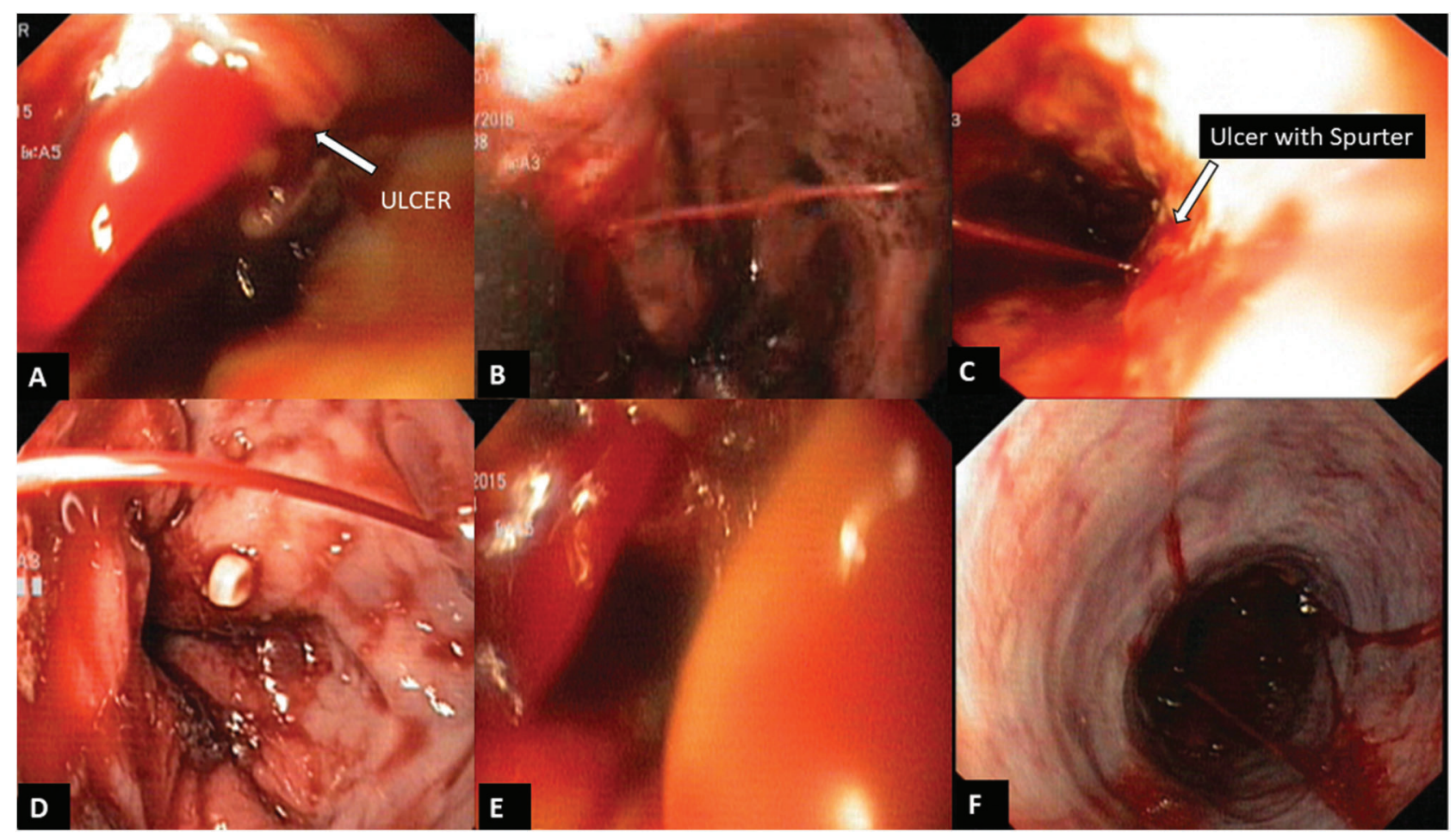

Fig. 1. Type A ulcer with spurting. (A, B) With EVL bands. (C-F) Without EVL bands.

reasons unrelated to the bleeding ( 3 and 2 developed spontaneous bacterial peritonitis and pneumonia, respectively, and one patient each experienced intra cranial bleed and acute kidney injury). The mortality rate of the control group (7 patients) was significantly less than that of the PEBU case group (46 patients). Of the deaths reported in the PEBU group, 32 patients died within five days of bleeding and the remaining 14 died over the next 6 -week period. Out of total deaths eight died after the TIPS procedure, all within five days of the bleed; 9 patients survived after TIPS. Two patients with

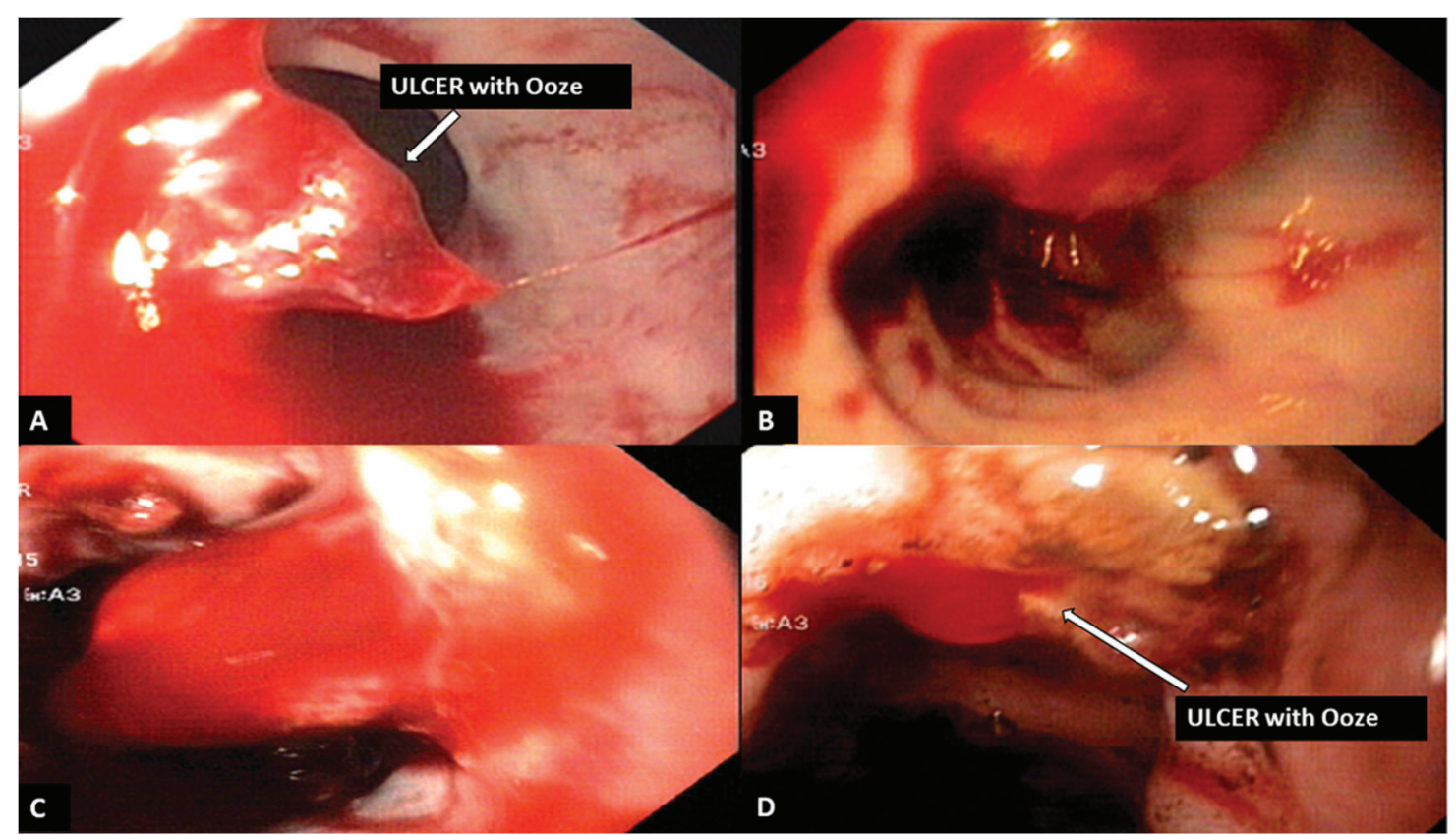

Fig. 2. Type B ulcer with ooze. Bleeding can be noted (A, B) with EVL bands in situ, and (C, D) without EVL bands. 
Jamwal K.D. et al: Post-EVL bleeding ulcers in liver disease

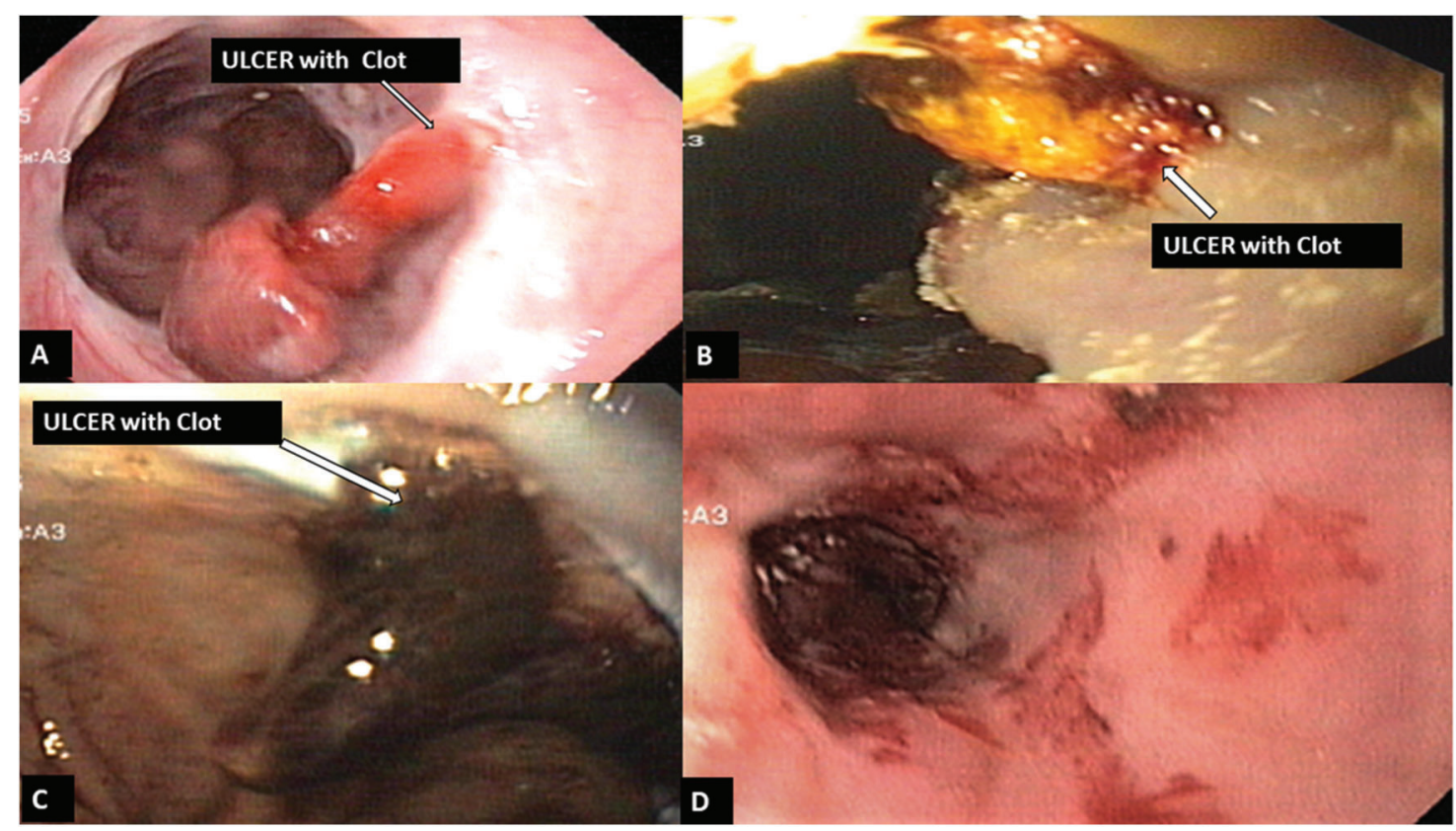

Fig. 3. Type $C$ ulcer with visible clots, scab or exudates from the ulcer without any bleeding.

portal vein thrombosis died, one within five days and one within six weeks of bleeding.

In the case group, deaths within five days were due to the following: worsening liver failure (with elevated MELD-Na and CTP score); sepsis (blood culture positive in two patients); acute kidney injury, as per AKIN (acute kidney injury network) criteria; and pneumonia (new onset chest infiltrates on chest $\mathrm{x}$-ray or chest computed tomography with productive sputum). Causes of death over the following 6-week period were related to sepsis (spontaneous bacterial peritonitis, pneumonia, blood culture positive) and organ failures (grade IV hepatic encephalopathy, and acute kidney injury).

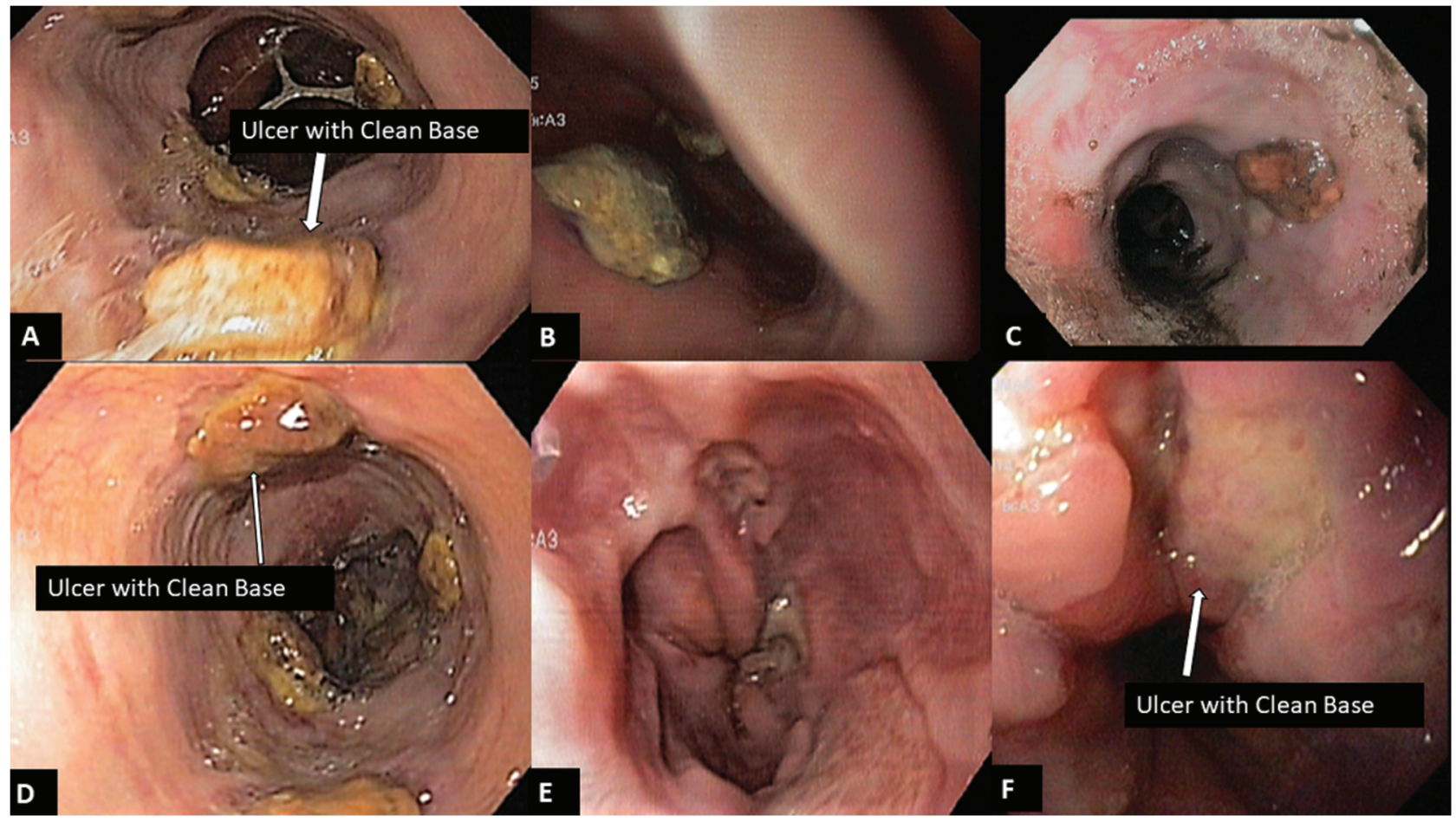

Fig. 4. Type D ulcer with pigmented or clear base. 
Table 2. Patients characteristics in the case PEBU and EVL control groups $^{a}$

\begin{tabular}{|c|c|c|c|}
\hline & PEBU & Control & $p$ \\
\hline Age, y & $\begin{array}{l}46.1 \pm \\
12.5\end{array}$ & $\begin{array}{l}47.2 \pm \\
10.2\end{array}$ & 0.61 \\
\hline Gender, male/female & $126 / 15$ & $129 / 12$ & 0.82 \\
\hline EVL indication & & & 0.73 \\
\hline Primary & 20 & 25 & \\
\hline Secondary & 121 & 116 & \\
\hline HVPG, $\mathrm{mmHg}{ }^{\mathrm{b}}$ & $18.8 \pm 5.6$ & - & - \\
\hline Variceal rebleeding & $11.4 \pm 5.1$ & - & - \\
\hline Variceal appearance ${ }^{c}$ & & & 0.98 \\
\hline Size $^{d}$ & $1.4 \pm 0.49$ & $1.2 \pm 0.45$ & \\
\hline Red color & 22 & 17 & \\
\hline Cherry red spots & 35 & 36 & \\
\hline Platelet plug & 8 & 7 & \\
\hline None of the above & 76 & 81 & \\
\hline MELD-Na score & $21.6 \pm 8.5$ & $21 \pm 7$ & 0.65 \\
\hline CTP score & $7.8 \pm 1.2$ & $8.2 \pm 1.2$ & 0.88 \\
\hline TIPS & 19 & - & - \\
\hline \multicolumn{4}{|l|}{ Ulcer type, $n$ (\%) } \\
\hline$A$ & $25(17.7)$ & - & - \\
\hline$B$ & $37(26.2)$ & - & - \\
\hline C & $51(36.3)$ & - & - \\
\hline$D$ & $28(19.8)$ & - & - \\
\hline $\begin{array}{l}\text { Esophageal } \\
\text { alterations }^{e}\end{array}$ & & & 0.09 \\
\hline Present & 49 & 56 & \\
\hline Absent & 92 & 85 & \\
\hline Bands deployed & $3.2 \pm 2.05$ & $3 \pm 2.5$ & 0.75 \\
\hline
\end{tabular}

Factors in the univariate analysis included age, gender, day of bleeding after EVL, size of the varices, MELD-Na and CTP scores, endoscopy appearance of the esophageal mucosa, HVPG, TIPS, and number of bands applied (Table 3). On multivariate analysis, only the MELD-Na score and endoscopic appearance of the ulcer were significant, with ORs of 1.23 and 11.64 respectively (Table 4 ). The PEBU types $A$ and $B$ were most significant; the $p$ values for the MELD-Na scores were 0.016 and 0.02 , receptively, and the ORs 11.64 (CI 1.59-85) and $3.12(0.5-17.6)$.

\section{Discussion}

This retrospective study investigated associations between the endoscopic morphology of PEBUs and patient mortality. No correlation was found between the incidence of sepsis and bleeding. PEBUs were classified based on their endoscopic appearance in descending order A-D. Of 3854 EVL procedures, $3.6 \%$ patients developed PEBU, and of those $32.6 \%$
Jamwal K.D. et al: Post-EVL bleeding ulcers in liver disease

Table 3. Variables in the univariate analysis ${ }^{a}$

\begin{tabular}{|c|c|c|c|}
\hline & $n$ & $p$ & $\mathrm{OR}(\mathrm{CI})$ \\
\hline Age, y & $46.1 \pm 12.5$ & 0.44 & $\begin{array}{l}0.99 \\
(0.96-1.02)\end{array}$ \\
\hline $\begin{array}{l}\text { Gender, male/ } \\
\text { female }\end{array}$ & $126 / 15$ & 0.366 & $\begin{array}{l}0.56 \\
(0.16-1.96)\end{array}$ \\
\hline $\begin{array}{l}\text { HVPG in } 54 \\
\text { patients }\end{array}$ & $18.8 \pm 5.6$ & 0.94 & $\begin{array}{l}1.01 \\
(0.96-1.04)\end{array}$ \\
\hline \multicolumn{4}{|l|}{$\begin{array}{l}\text { Etiology of liver } \\
\text { disease }\end{array}$} \\
\hline Alcohol & 75 & - & - \\
\hline Hepatitis C & 23 & - & - \\
\hline Hepatitis B & 20 & - & - \\
\hline NASH & 15 & - & - \\
\hline Other $^{b}$ & 8 & - & - \\
\hline $\begin{array}{l}\text { Variceal } \\
\text { rebleeding }\end{array}$ & $11.4 \pm 5.1$ & 0.10 & $\begin{array}{l}0.94 \\
(0.88-5.4)\end{array}$ \\
\hline Variceal size ${ }^{c}$ & $1.4 \pm 0.49$ & 0.72 & $\begin{array}{l}0.97 \\
(0.3-11.4)\end{array}$ \\
\hline MELD-Na score & $21.6 \pm 8.5$ & 1.28 & $\begin{array}{l}2.5 \\
(1.2-1.4)\end{array}$ \\
\hline CTP score & $7.8 \pm 1.2$ & 0.89 & $\begin{array}{l}1.11 \\
(0.82-1.18)\end{array}$ \\
\hline TIPS & 19 & 1.56 & $\begin{array}{l}1.56 \\
(0.5-4.23)\end{array}$ \\
\hline \multicolumn{4}{|l|}{ Ulcer type, $n(\%)$} \\
\hline$A$ & $25(17.7)$ & 0.001 & $\begin{array}{l}14.87 \\
(3.6-61.4)\end{array}$ \\
\hline B & $37(26.2)$ & 0.06 & $\begin{array}{l}3.4 \\
(0.95-12.3)\end{array}$ \\
\hline C & $51(36.3)$ & 0.88 & $\begin{array}{l}1.1 \\
(0.2-4.1)\end{array}$ \\
\hline $\mathrm{D}$ & $28(19.8)$ & 0.10 & $\begin{array}{l}0.94 \\
(0.88-5.4)\end{array}$ \\
\hline \multicolumn{4}{|l|}{$\begin{array}{l}\text { Esophageal } \\
\text { alterations }\end{array}$} \\
\hline Present & 49 & 0.16 & $\begin{array}{l}0.68 \\
(0.1-0.45)\end{array}$ \\
\hline Absent & 92 & & \\
\hline Bands & $3.2 \pm 2.05$ & 0.99 & $\begin{array}{l}0.99 \\
(0.82-1.2)\end{array}$ \\
\hline \multicolumn{4}{|l|}{$\begin{array}{l}\text { Mortality by ulcer } \\
\text { type }^{d}\end{array}$} \\
\hline$A$ & 18 & 0.001 & $\begin{array}{l}14.87 \\
(3.6-61.4)\end{array}$ \\
\hline B & 14 & 0.06 & $\begin{array}{l}3.4 \\
(0.95-12.3)\end{array}$ \\
\hline $\mathrm{C}$ & 10 & 0.88 & $\begin{array}{l}1.1 \\
(0.2-4.1)\end{array}$ \\
\hline $\mathrm{D}$ & 4 & 0.10 & $\begin{array}{l}0.94 \\
(0.88-5.4)\end{array}$ \\
\hline
\end{tabular}

(continued) 
Table 3. (continued)

\begin{tabular}{llll}
\hline & $n$ & $p$ & OR (CI) \\
\hline $\begin{array}{l}\text { Mortality in the } \\
\text { first 5 days }\end{array}$ & 32 & - & - \\
$\begin{array}{l}\text { Mortality within } 6 \\
\text { weeks }\end{array}$ & 14 & - & - \\
Methods to & & & \\
control bleeding & & & \\
$\quad$ Glue or & 75 & - & - \\
sclerosant & & & - \\
$\quad$ SB tube & 15 & - & - \\
$\quad$ Repeat EVL & 14 & - & - \\
$\quad$ SEMS & 16 & - & - \\
$\quad$ TIPS & 19 & - & - \\
Liver transplant & 2 &
\end{tabular}

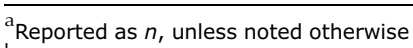

bautoimmune, cryptogenic

${ }^{\mathrm{c}} 1$, small; 2 , large

$\mathrm{d}_{\text {total mortality was }} 46$ patients.

suffered mortality. Of those who died, for $76 \%$ death occurred within five days, and 39.1, 30.4, 21.7, and 8.8\% had PEBU types $A, B, C$, and $D$, respectively. The MELD-Na score and PEBU type severity correlated positively with mortality. After adjusting for MELD-sodium score, mortality was best predicted by a type-A ulcer. Thus, stratifying patients based on PEBU type during the first five days after presentation can help predict mortality, independent of the MELD-sodium score, and can inform the treatment strategy.

PEBU has been reported to occur in $3 \%$ to $9 \%$ of patients; Grothaus et al. ${ }^{4}$ and Cho et al. ${ }^{5}$ reported rates of $7.8 \%$ and $7.7 \%$, respectively. In the present study the incidence of PEBU was $3.6 \%$.

All the patients in the present study received prophylaxis with proton pump inhibitors and sucralfate syrup for at least 2 weeks. ${ }^{4,5,9,10}$ The use of sucralfate after EVL is a common practice. Sakr et al. ${ }^{11}$ demonstrated in a randomized controlled trial (RCT) that intake of sucralfate was associated with ulcers of smaller size and less risk of PEBU. There has been no further RCT that addressed the complications of sucralfate after EVL. ${ }^{12}$ In addition, a RCT by Shaheen et al. ${ }^{13}$ showed that, in patients who received proton pump inhibitors, 2 weeks after EVL the size of ulcers was smaller than that of patients who did not receive the drug. ${ }^{13-15}$ However, the overall complication rates and outcomes of the two groups were similar. Although RCTs have concluded that either sucralfate or proton pump inhibitors, when applied

Table 4. Results of the multivariate analysis

\begin{tabular}{lll}
\hline & $p$ & OR $(\mathrm{CI})$ \\
\hline MELD-Na & $<0.01$ & $1.28(1.16-1.43)$ \\
PEBU type & & \\
A & 0.016 & $11.64(1.59-85)$ \\
B & 0.02 & $3.12(0.5-17.6)$ \\
C & 0.82 & $0.87(0.14-5.1)$ \\
\hline
\end{tabular}

singly, may decrease post-EVL bleeding, ${ }^{7,12,14}$ there has been no study of their combined use to reduce the risk of post-EVL bleeding.

In the present study, the number of mortalities within five days of bleeding was higher than within the next six weeks (32 and 10 patients, respectively). This could be attributable to hepatic ischemia after a severe upper gastrointestinal bleed in a compromised liver, which leads to worsening liver failure, and predisposition to other insults such as sepsis, organ failures (e.g., acute kidney injury) or spontaneous bacterial peritonitis. 8,16

Grothaus et al. ${ }^{4}$ reported that post-EVL bleeding was observed around the tenth day after EVL, and the rate was positively associated with the severity of liver disease (reflected by CTP score), lower albumin, and lower prothrombin activity. They also noted that bacterial infections and elevated heart rate were associated with post-EVL bleeding, but univariate or multivariate analyses of the present study determined that these variables were not significant.

The first five days of PEBU is considered a crucial period for patients with severe liver disease, as uncontrolled bleeding may lead to further complications. The present study found that during these first five days, the classification of ulcers was predictive of the outcome. A study by Bambha et al. ${ }^{16}$ appears to concur, since it was reported that increased mortality $(40 \%)$ occurred within the first five days of the presentation of bleed; in the present study, $76 \%$ of patients with PEBU who died did so within the first five days. The higher mortality in the present study could be related to the high MELD-Na score and therefore more severe liver disease of our patients.

Although the patients in the present study were cared for in tertiary hospitals, many of those with PEBU types A and B did not survive. This indicates that changes in management strategy are required, with systemic therapies (TIPS and liver transplantation $)^{17}$ in addition to local therapies such as stent, injections, and sprays. For type $C$ and $D$ ulcers, the less aggressive local therapies may be sufficient. Therefore, the ulcer morphological classification, in addition to MELD-Na score, should guide treatment in PEBU. The present results warrant further validation.

In a small post mortem study, Polski et al. ${ }^{18}$ elegantly described the evolution of post-EVL changes in the morphology of esophageal varices. The present study found that, although ulcers began to develop four days after the EVL, most bleeding episodes were noted at days 10 to 13 . This is probably due to neovascularization, and during this time the scab over the ulcer is weak before the ulcer heals completely. In some patients with poor liver functions (reflected by elevated MELD-Na and CTP scores), ulcers were found even in the fourth week after EVL. This could be attributable to elevated portal pressure and poor coagulation functions.

In a recently published study from India, the patients who presented with refractory esophageal variceal bleeding in ACLF (acute-on-chronic liver failure) also had PEBU's. ${ }^{19}$ To control bleeding, these were managed with local therapies, such as placement of self-expandable metal stent (SEMS) for 1 to 2 weeks. The study showed that the placement of SEMS in these critically ill cirrhotic patients improved their survival and decreased mortality, compared with standard care. ${ }^{19}$

Various management strategies for PEBU's have been reported, such as Sengstaken-Blakemore tube placement, redeployment of EVL bands, sclerotherapy, glueinjections, 


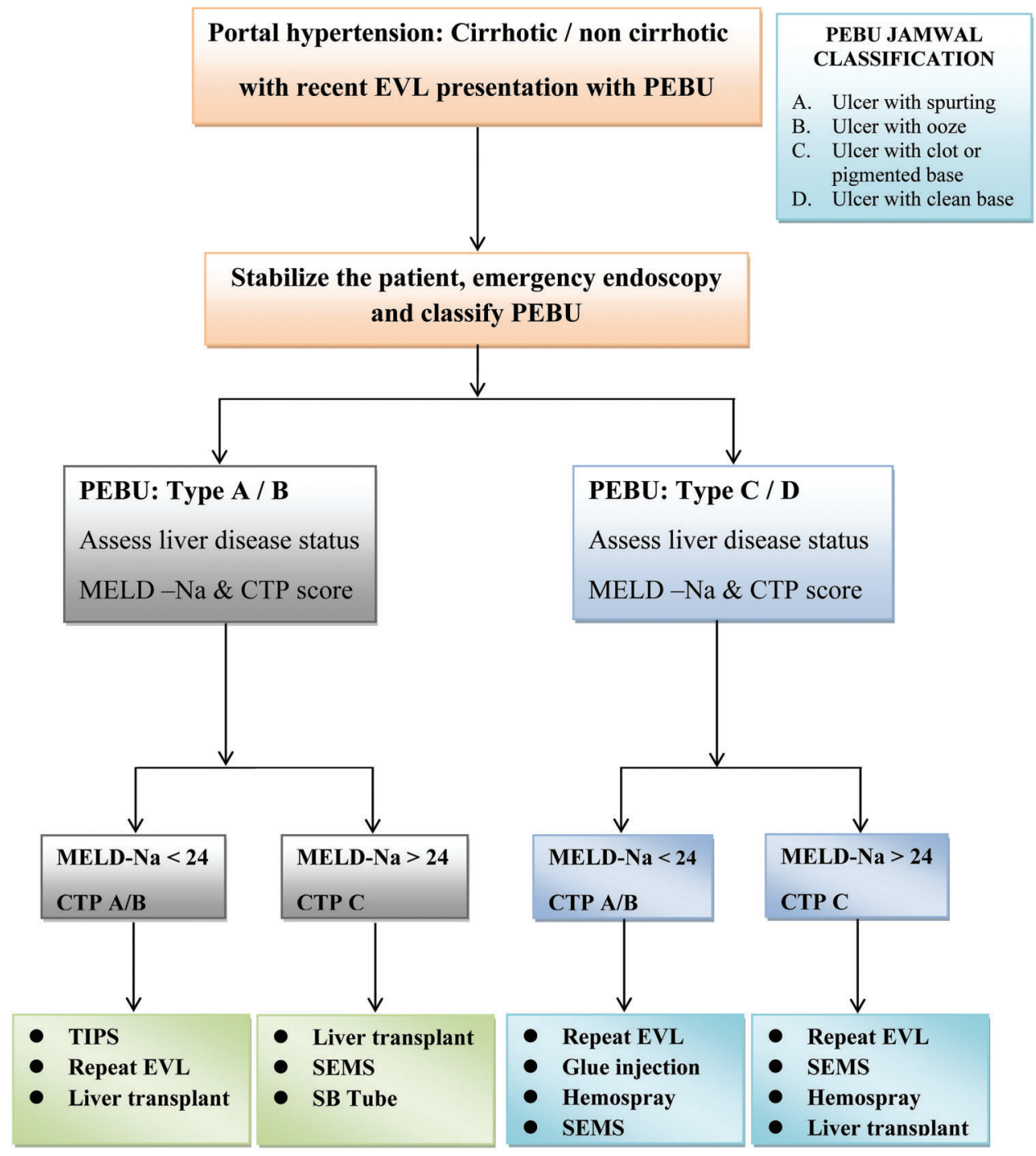

Fig. 5. Suggested algorithm for management of PEBU's of different clinical status.

SEMS, TIPS, and in some case reports, even liver transplantation. ${ }^{17,19-21}$ We found in the present retrospective study that PEBUs can be best managed according to the morphological classification of the ulcer, as the higher order types ( $A$ and $B$ ) were associated with highest mortality. Thus, the treatment strategy can be decided on the endoscopic appearance of the ulcer. However, a prospective and multicentric study is needed to validate these data.

Based on our experience we propose an algorithm for management of PEBU (Fig. 5), in which both the endoscopic appearance of the PEBU and the patient's liver disease status should be considered. If the ulcer classification is high (either type $A$ or $B$ ) and the liver disease severe (MELD-Na > 24 and CTP score $>8$ ), then the chances are low that these patients will respond to conventional methods of treatment such as glue injection at the bleeding ulcer, repeat EVL, or deployment of a SEMS. The likelihood of response to conventional therapies will be higher if the patient has good liver functions, even when the ulcer classification is high.

\section{Conclusions}

In this cohort of post-EVL patients, the rate of PEBU presentation was $3.6 \%$. Both the severity of liver disease (MELD$\mathrm{Na}$ ) and the morphological appearance of the ulcer were associated with patient's outcome in both the short term (five days) and long term (six weeks). The morphological appearance of the PEBU determined the outcome in these patients, independent of MELD-Na score. Thus, independent of the MELD-Na score, the classification of PEBU based on endoscopic appearance can help identify patients who will require systemic therapies, in addition to standard care.

\section{Conflict of interest}

The authors have no conflict of interests related to this publication.

\section{Author contributions}

Designed the study, created the management plan, and performed the follow-up (KDJ), contributed the clinical 
input, edited the manuscript, analyzed the data, and participated in the follow-up (MKS, RM, GK, SKS).

\section{References}

[1] D'Amico G, Pagliaro L, Bosch J. The treatment of portal hypertension: a meta-analytic review. Hepatology 1995;22:332-354. doi: 10.1002/hep. 1840220145.

[2] Calès P, Pascal JP. Natural history of esophageal varices in cirrhosis (from origin to rupture). Gastroenterol Clin Biol 1988;12:245-254.

[3] Garcia-Tsao G, Abraldes JG, Berzigotti A, Bosch J. Portal hypertensive bleeding in cirrhosis: Risk stratification, diagnosis, and management: 2016 practice guidance by the American Association for the study of liver diseases. Hepatology 2017;65:310-335. doi: 10.1002/hep.28906.

[4] Grothaus ], Petrasch F, Zeynalova S, Mössner ], Schiefke I, Hoffmeister A. Risk factors for bleeding complications after endoscopic variceal ligation therapy. Z Gastroenterol 2010;48:1200-1206. doi: 10.1055/s-00291245435.

[5] Cho $\mathrm{E}$, Jun $\mathrm{CH}$, Cho $\mathrm{SB}$, Park $\mathrm{CH}$, Kim HS, Choi SK, et al. Endoscopic variceal ligation-induced ulcer bleeding: What are the risk factors and treatment strategies? Medicine (Baltimore) 2017;96:e7157. doi: 10.1097/MD. 0000000000007157.

[6] Schmitz RJ, Sharma P, Badr AS, Qamar MT, Weston AP. Incidence and management of esophageal stricture formation, ulcer bleeding, perforation, and massive hematoma formation from sclerotherapy versus band ligation. Am J Gastroenterol 2001;96:437-441. doi: 10.1111/j.1572-0241.2001.03460.x.

[7] Vieira da Rocha EC, D'Amico EA, Caldwell SH, Flores da Rocha TR, Soares E, Silva CS, Dos Santos Bomfim V, et al. A prospective study of conventional and expanded coagulation indices in predicting ulcer bleeding after variceal band ligation. Clin Gastroenterol Hepatol 2009;7:988-993. doi: 10.1016/j.cgh. 2009.04.019.

[8] Senosiain Lalastra C, Arribas Anta J, Moreira Vicente V, Martínez González J, Maroto Castellanos M, García Sánchez MC, et al. Acute liver ischaemia after gastro-oesophageal variceal bleeding. Gastroenterol Hepatol 2016;39:590596. doi: 10.1016/j.gastrohep.2016.03.007.

[9] Vanbiervliet G, Giudicelli-Bornard S, Piche T, Berthier F, Gelsi E, Filippi J, et al. Predictive factors of bleeding related to post-banding ulcer following endoscopic variceal ligation in cirrhotic patients: a case-control study. Aliment Pharmacol Ther 2010;32:225-232. doi: 10.1111/j.1365-2036.2010. 04331.x.

[10] Sinclair M, Vaughan R, Angus PW, Gow PJ, Parker F, Hey P, et al. Risk factors for band-induced ulcer bleeding after prophylactic and therapeutic endoscopic variceal band ligation. Eur J Gastroenterol Hepatol 2015;27: 928-932. doi: 10.1097/MEG.0000000000000387.

[11] Sakr MA, Hamed WAE, El Gafaary MM, El-Folly RF. Role of sucralfate in promoting healing of post band variceal ulcer. Advances in Natural Science 2011. doi: $10.3968 /$ j.ans.1715787020110402.125.

[12] Yang WG, Hou MC, Lin HC, Kuo BI, Lee FY, Chang FY, et al. Effect of sucralfate granules in suspension on endoscopic variceal sclerotherapy induced ulcer: analysis of the factors determining ulcer healing. J Gastroenterol Hepatol 1998;13:225-231. doi: 10.1111/j.1440-1746.1998.tb00642.x.

[13] Shaheen NJ, Stuart E, Schmitz SM, Mitchell KL, Fried MW, Zacks S, et al. Pantoprazole reduces the size of postbanding ulcers after variceal band ligation: a randomized, controlled trial. Hepatology 2005;41:588-594. doi: 10.1002/hep.20593.

[14] Kang SH, Yim HJ, Kim SY, Suh SJ, Hyun JJ, Jung SW, et al. Proton pump inhibitor therapy is associated with reduction of early bleeding risk after prophylactic endoscopic variceal band ligation: A retrospective cohort study. Medicine (Baltimore) 2016;95:e2903. doi: 10.1097/MD. 0000000000002903.

[15] Garg PK, Sidhu SS, Bhargava DK. Role of omeprazole in prevention and treatment of postendoscopic variceal sclerotherapy esophageal complications. Double-blind randomized study. Dig Dis Sci 1995;40:1569-1574.

[16] Bambha K, Kim WR, Pedersen R, Bida JP, Kremers WK, Kamath PS. Predictors of early re-bleeding and mortality after acute variceal haemorrhage in patients with cirrhosis. Gut 2008;57:814-820. doi: 10.1136/gut.2007. 137489.

[17] Punamiya SJ, Amarapurkar DN. Role of TIPS in improving survival of patients with decompensated liver disease. Int J Hepatol 2011;2011:398291. doi: 10.4061/2011/398291.

[18] Polski JM, Brunt EM, Saeed ZA. Chronology of histological changes after band ligation of esophageal varices in humans. Endoscopy 2001;33:443-447. doi: $10.1055 / \mathrm{s}-2001-14259$.

[19] Maiwall R, Jamwal KD, Bhardwaj A, Bhadoria AS, Maras JS, Kumar G, et al. SX-ella stent danis effectively controls refractory variceal bleed in patients with acute-on-chronic liver failure. Dig Dis Sci 2018;63:493-501. doi: 10 . 1007/s10620-017-4686-8.

[20] Tierney A, Toriz BE, Mian S, Brown KE. Interventions and outcomes of treatment of postbanding ulcer hemorrhage after endoscopic band ligation: a single-center case series. Gastrointest Endosc 2013;77:136-140.e1. doi: 10.1016/j.gie.2012.08.031.

[21] Sarin SK, Kumar A, Angus PW, Baijal SS, Baik SK, Bayraktar Y, et al. Diagnosis and management of acute variceal bleeding: Asian Pacific Association for Study of the Liver recommendations. Hepatol Int 2011;5:607-624. doi: 10.1007/s12072-010-9236-9. 